\title{
Pemberdayaan Masyarakat sebagai Upaya Deteksi Dini Faktor Risiko Hipertensi
}

\section{Community Empowerment as an Early Detection of Risk Factors for Hypertension}

\author{
Ratna Indriawati ${ }^{1}$, Sherly Usman ${ }^{2}$ \\ Universitas Muhammadiyah Yogyakarta, Yogyakarta \\ 1ㄷ﹎indriawatiwibowo@yahoo.com, ${ }^{2}$ umiceli_1307@yahoo.com
}

Artikel: Dikirim 28 September 2018; Diterima 28 November 2018; Diterbitkan 30 November 2018

\begin{abstract}
Abstrak
Hipertensi masih merupakan masalah kesehatan yang penting. Prevalensi hipertensi nasional di Daerah Istimewa Yogyakarta (DIY) sebesar 35,8\% dengan proporsi kasus hipertensi yang telah didiagnosis oleh tenaga kesehatan sebesar 24\%. Hal ini berarti bahwa masih ada 76,0\% kasus hipertensi di masyarakat yang belum terdiagnosis. Tingginya angka insidensi hipertensi di propinsi DIY tersebut turut mempengaruhi insidensi penyakit ini di kabupaten Bantul. Pola makan yang tidak sehat dan kurang terjaga, perilaku merokok, stress psikososial karena faktor ekonomi, dan minimnya sarana \& prasarana kesehatan merupakan faktor pemicu tingginya insidensi penyakit hipertensi di wilayah ini. Pengabdian masyarakat ini bertujuan untuk memberikan tambahan pengetahuan faktor risiko, menanggulangi penyakit hipertensi dan komplikasi hipertensi serta pelatihan kader kesehatan terkait penyakit hipertensi. Kegiatan pengabdian masyarakat ini meliputi: melakukan pemeriksaan kesehatan dan faktor risiko hipertensi (berat badan, tinggi badan, dan body mass index/BMI) untuk skrining hipertensi, promosi kesehatan berupa penyuluhan hipertensi, pelatihan pengukuran tekanan darah yang baik dan benar, dan pembuatan dan pembagian leaflet hipertensi. Sebanyak 105 orang yang diperiksa tekanan darahnya, didapatkan 31 orang menderita hipertensi. Rentang umur kurang dari 40 tahun didapatkan 8 orang penderita hipertensi. Sedangkan kelompok umur 45-55 tahun juga didapatkan 8 orang dengan hipertensi. Terdapat 15 orang dengan hipertensi pada kelompok usia lebih dari 75 tahun.
\end{abstract}

Kata kunci: hipertensi, faktor risiko, tekanan darah, berat badan

\begin{abstract}
Hypertension is still the important health problem. The prevalence of national hypertension in the Special Region of Yogyakarta (DIY) was $35.8 \%$ with the proportion of cases of hypertension diagnosed by bealth personnel at $24 \%$. This means that there are still $76.0 \%$ cases of hypertension in the community that have not been diagnosed. The high incidence of bypertension in the province of DIY also affects the incidence of this disease in the Bantul district. Unhealthy and poorly maintained eating patterns, smoking behavior, psychosocial stress due to economic factors, and the lack of health facilities \& infrastructure are factors that trigger the high incidence of hypertension in this region. This community service aims to provide additional knowledge of risk factors, overcome bypertension and complications of bypertension and health cadres training related to bypertension. These community service activities included: conducting bealth checks and risk. factors for bypertension (body weight, height, and body mass index / BMI) for hypertension screening, health promotion in the form of bypertension counseling, excellent and correct blood pressure measurement training, and making bypertension leaflets. A total of 105 people who were tested for blood pressure were 31 people suffering from hypertension. The age range of fewer than 40 years found eight people with hypertension. Whereas the age group of 45-55 years also found eight people with hypertension. There are 15 people with hypertension in the age group over 75 years
\end{abstract}

Keywords: bypertension, risk factors, blood pressure, body weight

PENDAHULUAN

Analisis Situasi

1. Gambaran Umum Kelompok Sasaran a. Letak dan Kondisi geografi

Kabupaten Bantul merupakan salah satu dari lima Kabupaten yang ada di Propinsi Daerah Istimewa Yogyakarta, dengan luas 
wilayah seluruhnya mencapai 506,9 Km2 dan merupakan 15,91\% dari seluruh luas wilayah Propinsi DIY. Kabupaten Bantul terletak di bagian Selatan Wilayah Propinsi DIY, yaitu antara 07o 44'04" - 08o 00' 27'" LS dan 110o 12' 34" - 110o 31' 08" BT. Kecamatan Sewon merupakan salah satu kecamatan di kabupaten Bantul. Puskesmas Sewon I merupakan salah satu dari 27 Puskesmas yang ada di Kabupaten Bantul yang terletak di Desa Timbulharjo, Kecamatan Sewon, Kabupaten Bantul, dengan luas wilayah kerja terdiri dari 2 desa yaitu desa Timbuharjo dan desa Pendowoharjo yang terbagi atas 32 Dusun dengan 43 Posyandu dan 216 RT.Luas wilayah kerja Puskesmas Sewon I adalah $14,8 \mathrm{~km} 2$ yang terdiri dari desa Timbulharjo: $7,78 \mathrm{~km} 2$ dan desa Pendowoharjo: 6,98 km2 (Seksi Survailans \& Imunisasi, 2012).

Yogyakarta merupakan salah satu propinsi di Indonesia dengan prevalensi hipertensi yang tinggi. Menurut Riset Kesehatan Dasar (Riskesdas) 2007, prevalensi hipertensi nasional di Daerah Istimewa Yogyakarta sebesar 35,8\% dengan proporsi kasus hipertensi yang telah didiagnosis oleh tenaga kesehatan sebesar 24\%. Hal ini berarti bahwa masih ada $76,0 \%$ kasus hipertensi di masyarakat yang belum terdiagnosis. Tingginya angka insidensi hipertensi di propinsi DIY tersebut turut mempengaruhi insidensi penyakit ini di kabupaten Bantul (Seksi Survailans \& Imunisasi, 2012).

Pola makan yang tidak sehat dan kurang terjaga, perilaku merokok, stress psikososial karena faktor ekonomi, dan minimnya sarana \& prasarana kesehatan merupakan faktor pemicu tingginya insidensi penyakit hipertensi di wilayah ini. Dari data distribusi 10 besar penyakit pada puskesmas kabupaten/kota di provinsi DIY Periode Januari-Desember 2011 menunjukkan bahwa penyakit hipertensi masih menjadi penyakit tidak menular dengan prevalensi yang tinggi setelah influenza dan diare. Penyakit hipertensi dan strok menduduki peringkat pertama dan kedua pada pola kematian di Indonesia pada semua umur terutama pada kelompok umur 55- 64 tahun (Herke, 2006; Heriziana, 2017).

Hipertensi itu sendiri merupakan faktor resiko utama untuk penyakit serebrovaskular seperti stroke, transient ischemic attack, penyakit arteri koroner (infark miokard, angina), gagal ginjal, dementia, dan atrial fibrilasi. Bila penderita hipertensi disertai dengan komplikasi dengan penyakit penyerta tertentu maka akan meningkatkan mortalitas dan morbiditas akibat gangguan kardiovaskularnya tersebut. Tingginya prevalensi hipertensi beserta komplikasi dengan penyakit penyertanya tersebut di Yogyakarta, diperlukan suatu program pencegahan dan penanggulangan penyakit kardiovaskuler melalui program skreening terhadap faktor risiko kardiovaskuler dan penyuluhan tentang pencegahan penyakit kardiovaskuler. Program pencegahan dan penanggulangan penyakit hipertensi memerlukan peran aktif masyarakat. Oleh karena itu perlu usaha pemberdayaan masyarakat terhadap pengenalan faktor risiko, komplikasi dan deteksi dini hipertensi (Piepho, 2000; Rahajeng, 2009).

\section{METODE}

\section{Metode Pendekatan}

Metode pendekatan yang ditawarkan untuk mewujudkn tujuan dan realisasi program adalah kegiatan promosi kesehatan dan pelatihan. Serangkaian kegiatan mulai dari pemeriksaan tekanan darah, pemeriksaan skrining faktor risiko hipertensi dilanjutkan dengan pelatihan terstruktur dan pendampingan.

\section{Kegiatan Pengabdian}

Kegiatan pengabdian meliputi beberapa langkah. Kegiatan pengabdian yang yang merupakan langkah-langkah solusi atas persoalan adalah sebagai berikut:

1. Persiapan. Pada tahap persiapan Tim FKIK UMY bersama dengan Mitra 
menyusun rencana kegiatan, pendataan dan semua kebutuhan terkait pelaksanaan kegiatan.

2. Tahap Pelaksanaan. Pada tahap pelaksanaan, kegiatan dibagi menjadi 4 aktifitas yaitu:

a. Pemeriksaan tekanan darah. Pemeriksaan tekanan darah dilakukan oleh tim mahasiswa FKIK UMY yang sudah terlatih.

b. Skrining factor risiko hipertensi. Skrining faktor risiko dilakukan oleh dosen dan mahasiswa senior yang sudah terlatih. Tim FKIK UMY telah membentuk Tim dan telah melatih untuk melakukan kegiatan skrining.

c. Penyuluhan dan Edukasi hipertensi.

d. Pelatihan pengukuran tekanan darah yang benar kepada kader kesehatan.

e. Pembagian leaflet kepada pasien.

Untuk memastikan agar pengetahuan pasien terkait hipertensi menjadi lebih baik, maka dibagikan leaflet kepada pasien untuk dapat dipelajari di rumah. Hal ini bertujuan agar mereka tidak lupa dan dapat mempelajari kembali terkait hipertensi di manapun dia berada.

3. Laporan, evaluasi, dokumentasi dan data hasil kegiatan disusun dalam bentuk laporan tertulis sebagai bahan laporan. Pada naskah laporan juga diuliskan hasil evaluasi kegiatan disertai rekomendasi sesuai temuan yang didapatkan sehingga pelaksanaan berikutnya bisa berjalan lebih baik.

\section{HASIL DAN PEMBAHASAN}

Kegiatan pengabdian masyarakat dilaksanakan mulai bulan April 2018September 2018. Tahapan kegiatan pelaksanaan pengabdian masyarakat ini adalah sebagai berikut:

1. Membuat ijin pengabdian masyarakat

2. Ijin pengabdian dilakukan dengan cara menghubungi pihak perangkat desa dan menyampaikan maksud dari kegiatan pengabdian yang akan dilakukan.

3. Perkenalan program ke sasaran pengabdian Setelah mendapatkan ijin pengabdian selanjutnya tim melakukan pengenalan program pengabdian kepada sasaran pengabdian masyarakat. Hal ini dilakukan untuk memberikan gambaran kegiatan dan menyamakan persepsi kegiatan yang akan dilakukan. Kegiatan ini terlaksana pada tanggal 20 April 2018.

4. Pelatihan Kader Kesehatan

Pelatihan kader kesehatan tentang pengukuran tekanan darah serta promosi hipertensi. Materi pelatihan kader ini meliputi pengenalan alat-alat untuk pemeriksaan tekanan darah, menyampaikan informasi tentang tekanan darah dan hipertensi, dan melatih kader kesehatan cara pengukuran tekanan darah yang benar.

Gambar 1:

Pelatihan Kader Kesehatan

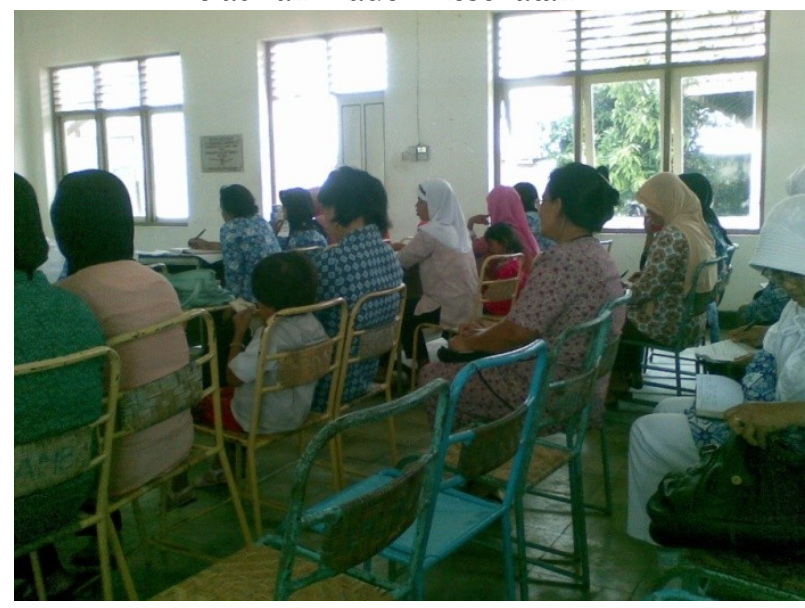


5. Pemeriksaan tekanan darah

Pemeriksaan tekanan darah untuk mengetahui faktor risiko sasaran terkait penyakit hipertensi. Sebanyak 105 orang yang diperiksa tekanan darahnya, didapatkan 31 orang menderita hipertensi. Rentang umur kurang dari 40 tahun didapatkan 8 orang penderita hipertensi. Sedangkan kelompok umur 45-55 tahun juga didapatkan 8 orang dengan hipertensi. Terdapat 15 orang dengan hipertensi pada kelompok usia lebih dari 75 tahun.

6. Skrining faktor risiko hipertensi

Skrining faktor risiko hipertensi telah dilakukan. Faktor risiko hipertensi yang diamati pada pengabdian ini meliputi BMI, dan kadar gula darah. Terdapat 3 orang yang mempunyai BMI di atas normal.

7. Pembagian leaflet hipertensi

Untuk memastikan

agar pengetahuan pasien terkait hipertensi menjadi lebih baik, maka dibagikan leaflet kepada pasien untuk dapat dipelajari di rumah. Hal ini bertujuan agar mereka tidak lupa dan dapat mempelajari kembali terkait hipertensi di manapun dia berada. Kegiatan ini sudah dilakukan pada tanggal 26 Juli 2018. Leaflet pengabdian yang kami lakukan sepert pada gambar di bawah ini (Gambar 2).

Gambar 2:

Leaflet hipertensi

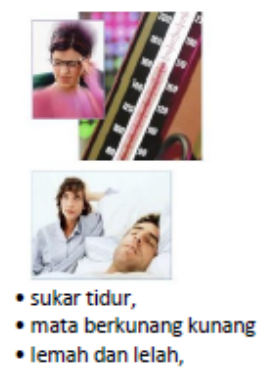

Komplikasi 1.Hipertensi ringan sampai sedang, jika tidak diobati, dapat dikaitkan dengan risiko penyakit aterosklerotik (penyumbatan arteri) pada $30 \%$ orang dan kerusakan organ pada $50 \%$ orang dalam 8-10 tahun setelah onset hipertensi 2.Kematian akibat penyakit jantung iskemik atau stroke meningkat secara progresif saat BP meningkat 3.Retinopati hipertensif ( Gangguan di retina) dikaitkan

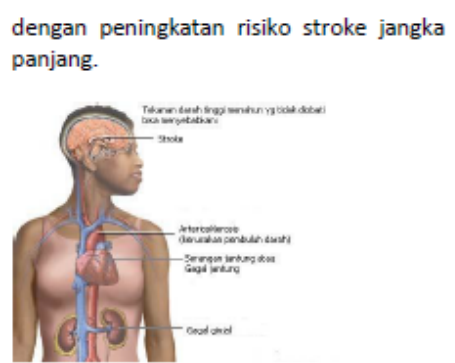

Hipertensi yang tidak terkendali akan meningkatkan risiko kematian dan sering digambarkan sebagai silent killer.

\section{Tata Laksana dan}

Pencegahan Hipertensi adalah kelainan seumur hidup, diperlukan komitmen jangka panjang terhadap modifikasi gaya hidup dan terapi obat-obatan

Strategi: 1.Pencegahan dan pengobatan obesitas: peningkatan indeks massa tubuh (BMI) dan lingkar pinggang dikaitkan dengan peningkatan risiko kardiovaskular yang tinggi, seperti hipertensi, diabetes melitus, glukosa puasa terganggu, dan hipertrofi ventrikel kiri [LVH]

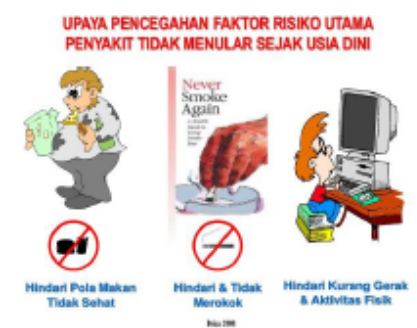

2.aktivitas fisik aerobik yang sesuai

3.Diet rendah garam, lemak total, dan kolesterol

4.Asupan makanan yang

cukup; kaya potassium, kalsium, dan magnesium

5.hindari konsumsi

alkohol , rokok, penggunaan obat-obatan terlarang, seperti kokain

\section{KESIMPULAN}

Kesimpulan dari pengabdian masyarakat ini adalah mitra bertambah ketrampilan dan pengetahuannya tentang pengukuran tekanan darah, hipertensi dan faktor risikonya.

\section{DAFTAR PUSTAKA}

Badan Penelitian dan Pengembangan Kesehatan, Departemen Kesehatan RI, 2002, Laporan SKRT 2001: Faktor Risiko Penyakit Tidak Menular, Studi Morbiditas dan Disabilitas. 
Depkes RI, 2006, Pedoman Teknis

Penemuan Dan Tatalaksana Penyakit Hipertensi, Direktorat P2PL, Jakarta.

Herke J.O. Sigarlaki, 2006, Karakteristik Dan Faktor Berhubungan Dengan Hipertensi Di Desa Bocor, Kecamatan Bulus Pesantren, Kabupaten Kebumen, Jawa Tengah,Tahun 2006, Makara Kesehatan, Vol. 10, No. 2: 7888.

Heriziana, 2017, Faktor Risiko Kejadian Hipertensi Di Puskesmas Basuki Rahmat Palembang, Jurnal Kesmas Jambi (JKMJ), Vol.1 No.1.

Kementerian Kesehatan, 2013, Riset Kesehatan Dasar (Riskesdas) 2012, Jakarta.

Piepho, RW. 2000, Overview The Angiotensin-Converting-EnzymeInhibitor. Am J ealth- Syst Pharm 57(Suppl 1) : S3-7.

Rahajeng E, 2009, Prevalensi Hipertensi dan Determinannya di Indonesia, Majalah Kedokteran Indonesia Vol. 59 No. 12

Seksi Survailans \& Imunisasi, 2012, Dinkes Provinsi DIY. Laporan STP Puskesmas: Pengamatan pada Penyakit Tertentu. 